\title{
Development and validation of early childhood care and education pre-service lecturer instrument
}

\author{
Shazlyn Milleana Shaharudin, Noorazrin Abd Rajak, Noor Wahida Md. Junus, Nor Azah Samat
}

Department of Mathematics, Universiti Pendidikan Sultan Idris, Malaysia

\begin{tabular}{l} 
Article Info \\
\hline Article history: \\
Received Dec 3, 2019 \\
Revised Jan 3, 2020 \\
Accepted Jan 12, 2020 \\
\hline
\end{tabular}

\section{Keywords:}

Early childhood care and education professionalism Instrument

Lecturer

Pre-school

Principal component analysis

\begin{abstract}
This paper presents to develop and validate the Early Childhood Care and Pre-Service Lecturer Instrument constructed to determine their level of competencies toward the quality of early childhood carers-educators' professionalism in Malaysia. Components which affect the early childhood quality were characterized through inclusive literature reviews alongside interviews conducted with experts and experienced lecturers. In this study, two experts were elected to review this instrument so as to enhance its validity while 70 more lecturers in Malaysia were involved. There are four scales in principal component analysis pertaining the quality of early childhood professionalism, namely: (1) disposition, (2) knowledge, (3) skills, and (4) practices. The component loading range or respective instrument item were between 0.56 and 0.79 , while the range for respective scales the alpha reliability coefficient were between 0.90 and 0.94 . Concisely, the findings from this study corroborated the weight and consistency of the ECCE Pre-Service Lecturer Instrument.
\end{abstract}

This is an open access article under the $\underline{C C B Y-S A}$ license.

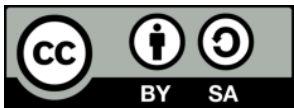

\section{Corresponding Author:}

Shazlyn Milleana Shaharudin,

Department of Mathematics, Faculty of Science and Mathematics,

Universiti Pendidikan Sultan Idris,

Tanjong Malim, Perak Darul Ridzuan 35900, Malaysia.

Email: shazlyn@fsmt.upsi.edu.my

\section{INTRODUCTION}

Early Childhood Care and Education (ECCE) program is one of UNESCO's utmost important programs that aims to develop a child's social, emotional, cognitive and physical needs holistically in order to build a solid and broad foundation for lifelong learning and wellbeing [1]. This program aligned with the Education 2030 Agenda to ensure that every children has access to quality early childhood development before attending primary education [2]. Upon this circumstance, a significant amount of research and initiatives had been implemented throughout the nation to improve and coordinate the ECCE carerseducators' competencies, professional development, and their career pathway respectively to be in line with this agenda [3-6].

Given the awareness and importance of this ECCE program, the Ministry of Education in 2003, had developed the National Preschools Curriculum and enforced all preschools to follow the law and rules respectively [7], and decided to impose a minimum qualification condition for all preschool teachers in the country. By the year 2020 all preschool teachers in Malaysia must possess a minimum qualification of a diploma in early childhood education [8]. Nevertheless, the development of early childhood education program in academic institutions has been arising tremendously around the globe [9, 10].

This issue leads to the training institutions of public and private universities/college whether they have offer and provide sufficient and adequate courses or programs on Early Childhood Care Education that 
will shaped the pre-service cares-educators. Work on this account, there are few relevant researches on the association between the qualification and the quality of the Early Childhood Care and Education [11-13].

Thus, taking these issues on the board, this study will explore and discuss on pre-service lecturer instrument of carers-educators' competencies, in particularly on disposition, knowledge, skills, and practices. With this issue in mind, the study is aimed to develop and validate which include principle component analysis method and Cronbach alpha as the reliability test method to a standard Early Childhood Care and Education (ECCE) Pre-Service Lecturer instrument to assess the better quality of Early Childhood Care and Education professional framework of instrument in Malaysia.

\section{RESEARCH METHOD}

\subsection{Development stage}

The intent of this study is to develop and validate the Early Childhood Care and Education Pre-Service Lecturer Instrument (ECCEPLI) using quantitative method and cross-sectional survey design. It is determined that the most fitting method was the quantitative method since the main focuses are: (i) to corroborate the entirety of the individuals' tendency of response and (ii) to explore the variation of tendencies amongst the involved participants. In this study, a three-stage approach was applied.

Figure 1 depicts three-stage approach was applied when developing ECCEPLI. In stage 1, the salient scales were identified. The purpose of this review is to determine which elements were regarded as important for the researchers, experts and practitioner as these elements are critical in developing the pre-school professionalism concerning the careers Educators. In this step, it was developing a set of preliminary scales which have for sections: disposition, knowledge, skills and practices. Two steps were essential in stage 2. First was to familiarize with the items that had been developed and develop more items for the newly identified scales. Secondly, distribute all of the set of items to be validated by an experts' team. Finally, Stage 3 included field testing the items, preceding the analysis of items and the validation process. These abovementioned procedures had been performed by [14-16].

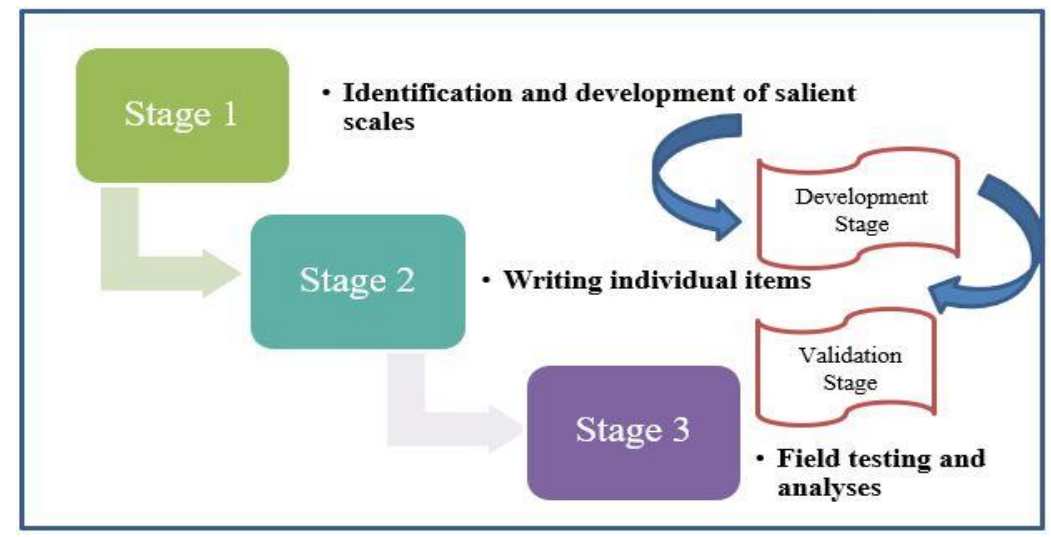

Figure 1. A three-stage approach was applied when developing ECCEPLI

\subsection{Validation stage}

Principal component analysis was carried out for two reasons: firstly, it was to improve the scales for ECCEPLI; and secondly, it was to deliver evidence pertaining how the enhanced scales were reliable and valid. The designation of Principal Component Analysis (PCA) moderates the dimension of huge data matrix to a lower dimension by maintaining the majority of the data's initial variability [17-19]. The accomplishment was made by the conversion of the observed potentially related variables into directly independent set of variables called principal components. The first principal component includes variations within the initial data extensively. In the interim, every following component include the outstanding variation subject significantly to being unrelated with the preceding component.

Covariance which is also known as correlation matrix obtained from the data matrix had a responsibility in PCA to compute the eigenvalues as well as eigenvectors. This would acquire the linked components comprising majority of the variations presented in the data [20,21]. This study used correlation matrix to reach its objectives [22]. The reduced matrix was the component matrix of eigenvector "loadings" 
which gave definition to the new variables. These consisted of linear transformation of the initial variables in which the variance in the new axes were capitalized.

There were five phases in the PCA algorithm. First, the input matrix was obtained. The correlation matrix was calculated. Next, the eigenvectors and eigenvalues of the correlation matrix were calculated. The utmost significant principal components were selected contingent on the accumulative percentage from the overall variation. Finally, an updated series of data were derived.

\subsection{Cronbach's alpha}

The analysis of data was done and the internal consistency reliability for the items interrelations was measured using Cronbach's Alpha $(\alpha)$ coefficient. Specifically, the extent of this measure where the items within a scale evaluates the same structures as the others in the same scale. All items which were less related to each scale were eliminated and each data were reexamined to the point where items that scored the lowest item-scale relations were omitted while the alpha coefficient is capitalized. The polished set of data analysis offer proofs to verify the dependability and factorial validity of the developed scales as a whole.

\section{RESULTS AND ANALYSIS}

For this study, all items which measured the significance and quality of the questions were validated using the PCA. The PCA for Early Childhood Care and Education Pre-Service Lecturer Instrument (ECCEPLI) initiated with 65 items. From the list, each item were split into four sections which are disposition, knowledge, skills and practices. Consequently, PCA was applied to the set of data in the respective sections to confirm if each item of a specific scale solely measured that scale [23].

The Eigenvalues were plotted by an $\mathrm{x}-\mathrm{y}$ axis. The point where the curve lowers and straightens are called the graph 'elbow'. It is known as the point where every component before and at the elbow need to be included. The PCA for ECCEPLI for disposition section started with 9 items. As analyzed, 9 items were gathered under a factor with Eigenvalue higher than 1. Scree Plot (Figure 2) also shows merely one point before starting to straighten. Hence, the fact that this scale consisted of only a component indicated that it can be accepted.

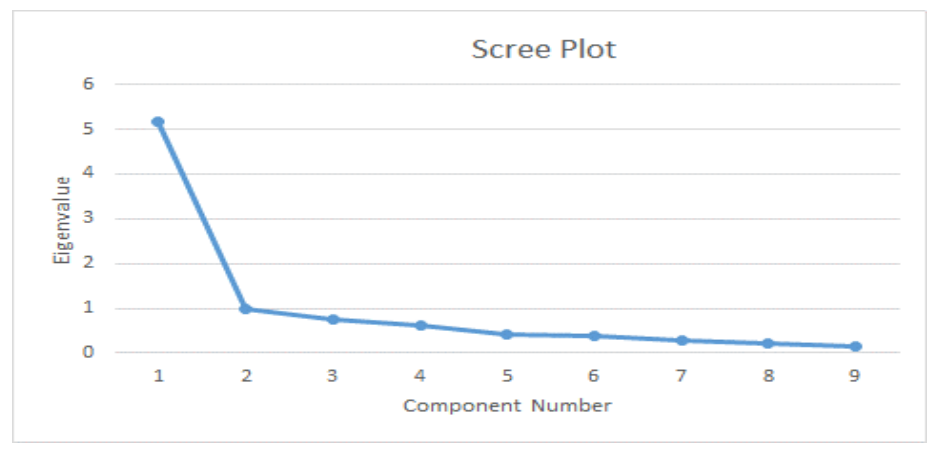

Figure 2. Principal component selection using a Scree Plot for disposition section

This component clarifies $57.52 \%$ of the complete variance while $42.48 \%$ of the variance remains unexplained. In social sciences' principle, the variance rates achieved between $40 \%$ and $60 \%$ are considered as adequate and recognized [24-26]. Table 1 shows Eigenvalues and a percentage of variance accounted by each factor in the ECCEPLI for disposition section. One scale was initially established for disposition field test of the ECCEPLI and, after PCA, the very scale attained all of the items in Table 1. All of the nine items gathered in one component with Eigenvalues higher than 1. The first component clarifies $57.52 \%$ of the whole variance which signifies the implication of this component for the set of data.

Items for every component and the respective component loadings for disposition section have load component higher than 0.50 are maintained in the PCA; therefore, no items were not eliminated. Gradually, the instrument was concluded with nine items.

The principal component analysis for ECCEPLI for knowledge section initiated with 16 items. As analyzed, 16 items are totalled beneath one factor with Eigenvalue higher than 1. Although both components two and three held eigenvalue higher than 1 , the first component should be significant enough to 
be maintained for the interpretation. Scree Plot (Figure 3), too, shows that only one point before it begins to straighten. Hence, it was accepted that the scale only has one component.

Table 1. Eigenvalues and percentage of variance accounted by each factor in the ECCEPLI for disposition section

\begin{tabular}{cccccccccc}
\hline & F1 & F2 & F3 & F4 & F5 & F6 & F7 & F8 & F9 \\
\hline Eigenvalue & 5.18 & 0.98 & 0.75 & 0.63 & 0.42 & 0.38 & 0.29 & 0.23 & 0.14 \\
Variability (\%) & 57.52 & 10.84 & 8.31 & 7.05 & 4.71 & 4.21 & 3.22 & 2.54 & 1.60 \\
& & & & & & 92.6 & & & \\
Cumulative \% & 57.52 & 68.36 & 76.67 & 83.72 & 88.43 & 4 & 95.86 & 98.40 & 100.00 \\
\hline
\end{tabular}

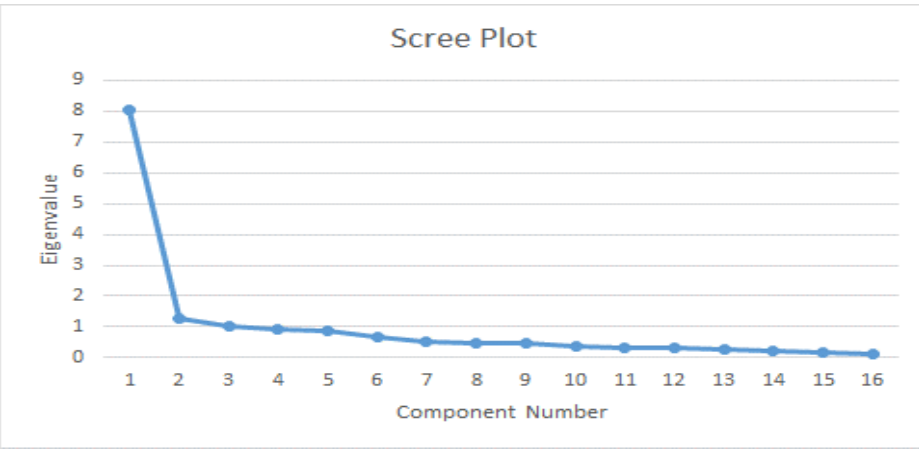

Figure 3. Principal component selection using a Scree Plot for knowledge section

This component clarifies $50.29 \%$ of the whole variance while $49.71 \%$ of the variance is unexplained. Table 2 illustrates the Eigenvalues and a percentage of variance explained by respective factor in the ECCEPLI for knowledge section. One scale was initially constructed for the knowledge field test of ECCEPLI. After PCA, the scale kept all of the items in Table 3, these 16 items cluster in one component with Eigenvalues higher than 1 . The first component clarifies $50.29 \%$ of the overall variance that signifies the important component for this set of data.

Items of each component and their component loadings for knowledge section have load component higher than 0.50 are maintained in the PCA; therefore, there is no items which had not been eliminated. Lastly, the instrument finished with 16 items.

Table 2. Eigenvalues and percentage of variance explained by each factor in the ECCEPLI for knowledge section

\begin{tabular}{lllllllllll}
\hline & F1 & F2 & F3 & F4 & F5 & F6 & F7 & F8 & F9 & F10 \\
\hline Eigenvalue & 8.05 & 1.26 & 1.02 & 0.91 & 0.86 & 0.66 & 0.54 & 0.48 & 0.46 & 0.38 \\
Variability (\%) & 50.29 & 7.88 & 6.36 & 5.70 & 5.37 & 4.15 & 3.38 & 3.01 & 2.85 & 2.37 \\
Cumulative \% & 50.29 & 58.17 & 64.53 & 70.23 & 75.60 & 79.76 & 83.13 & 86.15 & 88.99 & 91.37 \\
\hline
\end{tabular}

The principal component analysis for ECCEPLI for skills section started with 20 items. 19 items were gathered under one factor which had Eigenvalue higher than 1 based on the analysis. Although component two, three and four had eigenvalues higher than 1, the first was deemed to be significant to retain for interpretation. Scree Plot (Figure 4) also shows merely one point before it started to straighten. Hence, the accepted scale is only one component.

This one component clarifies $49.51 \%$ of the overall variance while $50.49 \%$ of the variance is still unexplained. Table 3 illustrates Eigenvalues and a percentage of variance described by every factor in the ECCEPLI for skills section. One scale was initially constructed for the knowledge field test of ECCEPLI and, after PCA, the same scale maintained all items, except item 27, these 19 items cluster into a component that had Eigenvalues higher than 1 . The first component clarifies $49.51 \%$ of the whole variance which showed the important component for this set of data.

Items of each component and their component loadings for skills section with load component higher than 0.50 which has been maintained in the PCA; therefore, an item (item 27) was eliminated. In the end, the instrument finished with 19 items. The principal component analysis for ECCEPLI for skills 
section started with 20 items. 19 items were gathered under two factors which had Eigenvalue higher than 1 based on the analysis. Although component two, three and four had eigenvalues higher than 1, the first and second were deemed to be significant to retain for interpretation. Scree Plot (Figure 5) also displays just two points before it straightened. Hence, the accepted scale are only two components.

Components one and two illuminate $39.34 \%$ and $12.81 \%$ of the overall variance while $47.85 \%$ of the variance is still unexplained. Table 4 displays Eigenvalues and a percentage of variance described by each factor in the ECCEPTI for practice section. One scale was initially constructed for the practice field test of ECCEPTI. After PCA, the same scale (one and two) maintained all items in Table 4, except for item 49. These 18 items cluster in two components had Eigenvalues higher than 1 . The first one clarifies $39.34 \%$ of the total variance, while the second clarifies $12.81 \%$ of the overall variance. As observed, both components clarify $52.15 \%$ from the whole variance.

Items of each component and their component loadings for practices section with load component higher than 0.50 are maintained in the PCA; so, one item (item 49) was eliminated. There were nine items with load values varying between 0.68 and 0.75 for the first factor. On the other hand, there was one item with the load value 0.72 for the second factor. The final item number for the instrument was 18 .

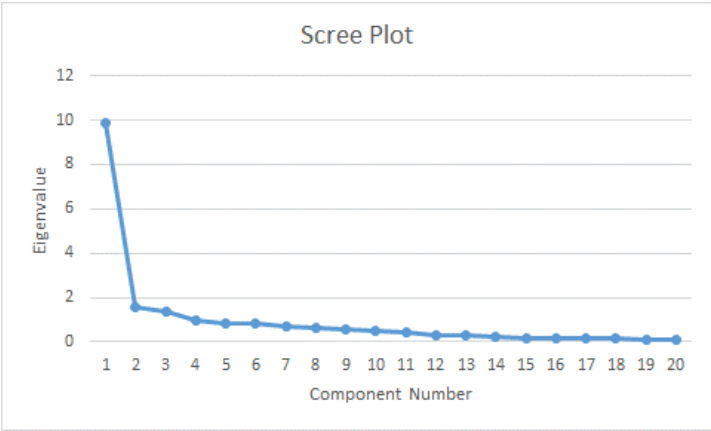

Figure 4. Principal component selection using a Scree Plot for skills section

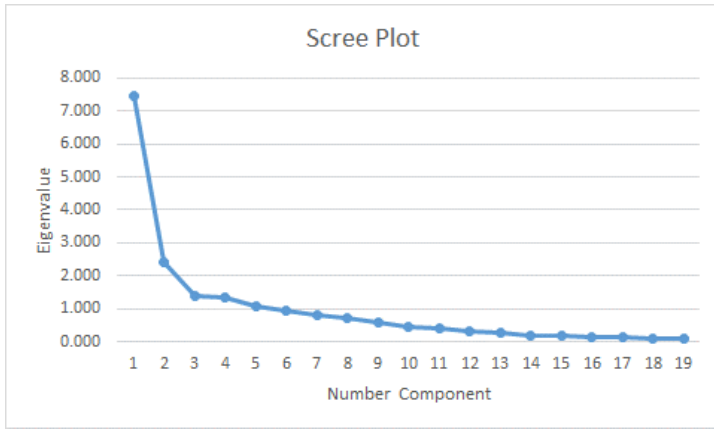

Figure 5. Principal component selection using a Scree Plot for practices section

Table 3. Eigenvalues and percentage of variance accounted by each factor in the ECCEPTI for skills section

\begin{tabular}{ccccccccccc}
\hline & F1 & F2 & F3 & F4 & F5 & F6 & F7 & F8 & F9 & F10 \\
\hline Eigenvalue & 9.90 & 1.56 & 1.34 & 1.00 & 0.85 & 0.81 & 0.68 & 0.61 & 0.54 & 0.53 \\
Variability (\%) & 49.51 & 7.80 & 6.70 & 5.00 & 4.25 & 4.04 & 3.42 & 3.04 & 2.70 & 2.67 \\
Cumulative \% & 49.51 & 57.30 & 64.00 & 69.00 & 73.25 & 77.29 & 80.71 & 83.75 & 86.45 & 89.12 \\
\hline
\end{tabular}

Table 4. Eigenvalues and percentage of variance accounted by each factor in the ECCEPTI for practices section

\begin{tabular}{lllllllllll}
\hline & F1 & F2 & F3 & F4 & F5 & F6 & F7 & F8 & F9 & F10 \\
\hline Eigenvalue & 7.48 & 2.43 & 1.39 & 1.33 & 1.06 & 0.96 & 0.83 & 0.73 & 0.57 & 0.46 \\
Variability (\%) & 39.34 & 12.81 & 7.34 & 7.02 & 5.59 & 5.04 & 4.35 & 3.83 & 2.99 & 2.40 \\
Cumulative \% & 39.34 & 52.15 & 59.49 & 66.51 & 72.10 & 77.14 & 81.49 & 85.31 & 88.31 & 90.70 \\
\hline
\end{tabular}

Table 5 presents the reliability for respectively developed ECCEPLI scale with the sample of 70 participants. The internal consistency reliability (coefficient alpha) for the four ECCEPLI scales ranged between 0.90 up to 0.97 . Specifically, the Cronbach's Alpha are 0.90 for disposition section, 0.93 for knowledge section, 0.94 for skills section, and 0.90 for practices section. By applying the general 'rule-ofthumb', the concluded range were considered good enough to be acceptable $[27,28]$ which the closeness of the alpha to 1 is highly related to the items' internal consistency.

This study seeks to establish reliable and valid instrument to evaluate ECCE preservice lecturer instrument. The draft scale was concluded with of 65 items and managed 70 participants who are also lecturers from all over Malaysia. Accordingly, based on the finalized instrument, 63 items with load component higher than 0.50 were kept in the PCA; while two of them (item 27 and item 49) were eliminated. There were four categories: disposition section, knowledge section, skills section and practices section. As analyzed, the instrument ECCEPLI was deemed to be highly reliable and its construct validity was 
effective which were beneficial for this study. It inimitably encompassed aspects of professionalism which could a great factor for the establishment of carers-educators in pre-schools. All of the aspects were selected from the finalized instruments, result of prior studies and oral conducts with the experienced pre-school teachers as well as some experts. Among the leads of the ECCEPLI were it was respondents friendly as they could manage and answer it with ease. It comprised four scales which overall had 65 items, considered to be accessible and adequate for the respondents to answer. Moreover, the grammar structures as well as the words choices in the ECCEPLI were comprehensively uncomplicated. Likewise, it was cost-effective and timely fitting. Based on $[29,30]$ due to the time limitations that teachers had, instrument response time must be short and not interruptive. ECCEPLI is additional to the current instruments, more specifically for evaluating the establishment of pre-school professionalism. The ECCEPLI also could also adapt and be applicable for numerous types of respondents and for diverse settings based on the researchers' necessity and ingenuity. Nonetheless, because it was meant to be used by pre-school teachers, the aspect of care was a priority.

Table 5. Scale reliability using Cronbach's Alpha coefficient for ECCEPLI

\begin{tabular}{ccc}
\hline Section & Number of Items & Cronbach's Alpha \\
\hline Disposition & 9 & 0.90 \\
Knowledge & 16 & 0.93 \\
Skills & 20 & 0.94 \\
Practices & 19 & 0.90 \\
\hline $\mathrm{N}=70$ & &
\end{tabular}

\section{CONCLUSION}

This paper reports the establishment and validation of an instrument designed to measure the level of competencies of ECCE pre-service lecturer. With an aim to assess carers-educators' professionalism, the ECCEPLI was established to serve additionally to the prior instruments. In conclusion, the results from this study had justified that the Early Childhood Care and Education Pre-Service Lecturer Instrument are valid and reliable. Nevertheless, additional research would further upgrade it by considering the characteristics differences of the respondents. This extensive step would be making a bigger room of improvement for the development of more dependable evaluation of the Early Childhood Care and Education Pre-Service Lecturer instrument.

\section{ACKNOWLEDGEMENTS}

This research study has received supports from the Ministry of Finance (MOF) via the aid of the Ministry of Education (MOE) Malaysia. For this study, we sincerely express our gratitude towards National Child Development Research Centre (NCDRC), Universiti Pendidikan Sultan Idris (UPSI) as the leading university in collaboration with SEGi University. This study is titled "Development of Comprehensive and Integrated Model of Quality Malaysian Early Childhood Care and Education (20150024-106-04) with the sub project is Project 2: Development of Carers-Educators' Professionalism" (20150024-106-04-02). It is subsidized by the Ministry of Finance through the Ministry of Education Malaysia. We would like to convey our thanks to the contributions of every member of the research team as well as the steering committee, valuable informants, teachers, parents and other stakeholders who took participation.

\section{REFERENCES}

[1] UNESCO, Early Childhood Care and Education, 2019.

[2] Ishimine, K. and Tayler, C., "Assessing quality in early childhood education and care," European Journal of Education Research, Development and Policy, vol. 49(2), pp. 272-290, 2014.

[3] Saracho, O. N. and Spodek, B., "Early childhood teachers' preparation and the quality of program outcomes," Early Child Development and Care, vol 177, no. 1, pp. 71-91, 2007.

[4] Saracho, O. N. and Spodek, B., Improving teacher quality, in: O. N. Saracho and B. Spodek (Eds). Studying teachers in early childhood settings (Greenwich, CT, Information Age Publishing), pp. 209-221, 2003.

[5] Saracho, O. N. and Spodek, B., "Preschool teachers' professional development, in: B. Spodek and O. N. Saracho (Eds)", Handbook of research on the education of young children, $2^{\text {nd }}$ ed, (New York, Erlbaum), pp. 423-439, 2006.

[6] Egert, F., Fukkink, R. G., and Eckhardt, A. G., "Impact of in-service professional development programs for early childhood teachers on quality ratings and child outcomes: a meta-analysis," Review of Educational Research, vol. 88, no. 3, pp. 401-433, 2018. 
[7] Curriculum Development Centre (CDC). Early childhood care and education policy implementation review. Putrajaya: Ministry of Education Malaysia, 2007.

[8] L. Foong, et al., "Private sector early child care and education in Malaysia: workforce readiness for further education," Kajian Malaysia, vol. 36, no. 1, pp. 127-154, 2018.

[9] Yenpiam, K., Sirisunhirun, S., and Wichitputchrapron, W., "Causal relationship model of factors affecting collaboration between local administrative organizations in early childhood education management in Thailand," Kasetsart Journal of Social Sciences, vol. 40, pp. 558-566, 2018.

[10] Gong, X. and Wang, P., "A comparative study of pre-service education for preschool teachers in China and the United States. Current Issues in Comparative Education (CICE)”, vol. 19, no. 2, pp. 84-110, 2017.

[11] Manning, M., Garvis, S., Fleming, C., and Wong, G. T. W., "The relationship between teacher qualification and the quality of the early childhood care and learning environment: A systematic review," Campbell Systematic Reviews, vol. 1, pp. 13-21, 2017.

[12] Manning, M., Wong, G. T. W., Fleming, C., and Garvis, S., "Is teacher qualification associated with the quality of the early childhood education and care environment? A meta-analytic review," Review of Educational Research, vol. 18, no. 3, pp. 370-415, 2019.

[13] Melinda, C., Judit, F., Agnes, N., and Judit, P., "Research on the health literacy of professionals working in early childhood education," Kontakt, vol. 20, no. 4, pp. 356-362, 2018.

[14] S. Walker and B. Fraser, "Development and validation of the instrument assessing distance education learning environments in higher education: The Distance Learning Environment Survey (DELES)," Learning Environments Research: An International Journal, vol. 8, no. 3, pp. 289-308, 2005.

[15] C. N. Che Ahmad, et al., "The Establishment of Physical Aspects of Science Laboratory Environment Inventory (PSLEI)," Journal of Turkish Science Education, vol. 11, no. 2, pp. 123-136, 2014.

[16] C. N. Che Ahmad, et al., "An instrument to assess physical aspects of classroom environment in Malaysia," International Journal of Arts and Science, vol. 8, no. 2, pp. 1-12, 2015.

[17] S. M. Shaharudin, et al., "Identification of rainfall patterns on hydrological simulation using robust principal component analysis," Indonesian Journal of Electrical Engineering and Computer Science (IJEECS), vol. 11, no. 3, pp. 1162-1167, 2018.

[18] H. Sabrol, et al., "Recognition of tomato late blight by using DWT and component analysis," Indonesian Journal of Electrical Engineering and Computer Science (IJEECS), vol. 7, no. 1, pp. 194-199, 2017.

[19] S.M. Shaharudin, et al., "Classification of daily torrential rainfall patterns based on a robust correlation measure," International Journal of Advanced Science and Technology, vol. 28, no. 8s, pp. 251-259, 2019.

[20] S.M. Shaharudin, et al., "The comparison of t-mode and pearson correlation matrices in classification of daily rainfall patterns in Peninsular Malaysia," Matematika, vol. 29, no. 1c, pp. 187-194, 2013.

[21] S. M. Shaharudin, et al., "An efficient method to improve the clustering performance using hybrid robust principal component analysis-spectral biclustering in rainfall patterns identification," International Journal of Artificial Intelligence (IJ-AI), vol. 8, no. 3, pp. 1162-1167, 2019.

[22] M.S. Samsudin, et al., "Assessment of seasonal and spatial surface marine water quality variation in Semerak River Estuary, Malaysia," International Journal of Engineering and Technology, vol. 7. No. 4.43, pp. 29-35, 2018.

[23] N.M.N. Mathivanan, et al., A comparative study on dimensionality reduction between principal component analysis and k-means clustering," Indonesian Journal of Electrical Engineering and Computer Science (IJEECS), vol. 16, no. 2, pp. 752-758, 2019.

[24] T. Kutluca, "Developing a scale to measure information and communication technology utilization levels," Journal of Turkish Science Education, vol. 7, no. 4, pp. 37-45, 2010.

[25] C. N. Che Ahmad, et al., "Development and validation of teacher perception on Early Childhood Care and Education Curriculum Instrument (ECCECI)," International Journal of Academic Research in Business and Social Sciences, vol. 8, no. 1, pp. 716-727, 2018.

[26] L.N. Sharma, et al., "Multiscale PCA based quality controlled denoising of multichannel ecg signals," Internationcal Journal of Information and Electronics Engineering, vol. 2, no. 2, pp. 107-111, 2012.

[27] D. George and P. Mallery, SPSS for Windows Step by Step: A Simple Guide and Reference 10.0 update, $3^{\text {rd }}$ ed. Toronto: Allyn and Bacon, 2001.

[28] N.F. Habidin, "Sustainable performance measures for Malaysian Automotive Industry," World Applied Sciences Journal, vol. 33, no. 6, pp. 1017-1024, 2015.

[29] B. Lewthwaite, "The development, validation and application of a science curriculum delivery evaluation questionnaire for francophone-minority settings," Canadian Journal of Science, Mathematics and Technology Education, vol. 7, no. 4, pp. 335-354, 2007.

[30] R.C.F. Sun and D.T.L. Shek, "Student classroom misbehaviour: An exploratory study based on teachers' perceptions", vol. 2012, pp. 1-8, 2012. 